\title{
Saying and believing: the norm commonality assumption
}

\author{
Mona Simion ${ }^{1}$
}

\begin{abstract}
One very popular assumption in the epistemological literature is that belief and assertion are governed by one and the same epistemic norm. This paper challenges this claim. Extant arguments in defence of the view are scrutinized and found to rest on value-theoretic inaccuracies. First, the belief-assertion parallel is shown to lack the needed normative strength. Second, I argue that the claim that assertion inherits the norm of belief in virtue of being an expression thereof rests on a failed instance of deontic transmission. Third, the inheritance argument from the norm for action is proven guilty of deontic equivocation. Last but not least, it is argued that, on a functionalist normative picture, assertion and belief are governed by different epistemic norms, in virtue of serving different epistemic functions.
\end{abstract}

Keywords Epistemic norm · Commonality · Assertion · Belief · Belief-assertion parallel

\section{Introduction}

It looks as though there's a clear sense in which you should only say things you actually believe; after all, we criticize each other all the time for doing otherwise: 'You don't believe that yourself!', or 'Why would you say such a thing? Do you really believe it to be true?' are fairly common ways to challenge assertions. Several philosophers take this to suggest that, if there is such a thing as a particular

Mona Simion

SimionescuM@cardiff.ac.uk;

http://www.mona-simion.com

1 Cardiff University, Cardiff, UK 
epistemic standard governing our speech acts and mental states, ${ }^{1}$ in the case of belief and assertion, it is one and the same. This has become known in the literature as 'the belief/assertion norm commonality assumption' (henceforth the commonality assumption, or CA for short). ${ }^{2}$

This paper questions the commonality assumption. In order to do that, first, I examine extant motivations for believing CA to be true and argue that, at closer inspection, they fail to support Commonality. I identify two broad types of defence: first (Sect. 2), there are people who believe that, in a relevant way, belief and assertion are essentially the same kind of beast, only manifested in different environments ["the belief-assertion parallel", notably defended in Adler (2002)]. Importantly, these philosophers also take this metaphysical parallelism to have import in the normative realm. Let us dub these arguments 'normative correspondence' arguments.

Secondly (Sect. 3), I will be looking at what Brown (2012) dubs 'inheritance arguments'; according to these lines of defence, belief and assertion are governed by one and the same epistemic norm in virtue of the fact that they either inherit it from each other, or from a common source. For instance, concerning the latter, one popular line argues that, since both belief and assertion ultimately serve to store/communicate actionable information, they will both inherit their epistemic norm from action. I argue that both routes are in need of further defence.

Finally, in Sect. 4, I look at a simple functionalist normative picture for assertion and belief, and argue that it supports non-commonality. Finally, in (Sect. 5) I conclude.

\section{Normative correspondence}

One can defend the commonality assumption without offering much in the way of theoretical grounds ${ }^{3}$ to believe it to be true. One can do this by merely independently defending one and the same norm, in our case, for both assertion and belief, or on mostly empirical grounds, by noting that intuitions concerning propriety tend to go hand in hand for the two. However, this view does not propose any deeper underlying motivation for assertion and belief being governed by one and the same norm. For all it is shown, norm commonality for assertion and belief might be a mere accident.

Since it is rather implausible that this should be so, for the purposes of this paper, I would like to set this strategy aside; after all, it would surely be theoretically more satisfactory if we managed to identify a motivation to believe CA holds. ${ }^{4}$

\footnotetext{
${ }^{1}$ Here and below, what is discussed is the necessity claim involved in whatever the norm at stake.

2 For champions of CA, see, e.g. (Bach 2008; Hindriks 2007; Douven 2006; Williamson 2000).

3 I borrow from Brown's (2012) illuminating discussion of assertion/action commonality when it comes to categorizing lines of defence.

${ }^{4}$ Supporters of the first strategy might argue that theoretical considerations pertaining to parsimony recommend their theory over non-commonality. Note, though, that parsimony is only an all-else-equal virtue. For instance, we would not want to say that a theory that postulates commonality for inner city and Formula 1 driving is preferable to a theory that does not. What this seems to suggest is that commonality
} 
And, indeed, several strategies proposed in the literature belong here. Let us start with what I have dubbed 'the normative correspondence proposal'. Recall that one very widely spread assumption in recent literature on epistemic norms is that the 'belief-assertion parallel' (henceforth BAP) has a special kind of normative import. That is, several prominent philosophers [e.g. Williamson (2000); Douven (2006); Sosa (2010)] employ the thesis that, roughly put, belief stands to assertion like inner to outer, to argue from the epistemic norm governing one to the epistemic norm governing the other. It is assumed, then, that metaphysical parallelism licenses norm correspondence.

This section questions this extremely popular assumption. ${ }^{5}$ To this effect, I first argue that, in its most plausible formulation, the belief-assertion parallel lacks any normative import. Further on, I turn to two remaining possible readings of BAP in an attempt to shed serious doubts on their plausibility and normative strength.

\subsection{Like inner to outer}

To begin with, I want to get one worry out of the way: one might be tempted to object to BAP on metaphysical grounds: after all, belief is a state, while assertion is an action. This line, however, will not concern us much here, since I take it not to constitute an insurmountable difficulty for the champion of BAP; she could, for instance, replace belief for judgement, or belief-formation. ${ }^{6}$ As such, I will set this worry aside.

In Tim Williamson's reading, the belief assertion parallel amounts to the claim that:

BAP Believing $p$ stands to asserting $p$ as the inner stands to the outer (2000, 255-56)

Given BAP, and having offered extensive argument for a knowledge norm of assertion, Williamson goes on to argue for a knowledge norm of belief:

It is plausible [...] that occurrently believing $p$ stands to asserting $p$ as the inner stands to the outer. If so, the knowledge rule for assertion corresponds to the norm that one should believe $p$ only if one knows $p$ (2000, 255-256).

Let us spell this out. It looks as though Williamson takes BAP to warrant the following normative claim:

Norm Correspondence (NC) If belief (assertion)is governed by norm N, then assertion (belief) is governed by norm $\mathrm{N}$ also

\footnotetext{
Footnote 4 continued

will be a virtue insofar as we have reason to believe that belief and assertion are, in some relevant respects, similar beasts. For discussion of this line of argument, see the next section.

${ }^{5}$ For an older, more sophisticated version of this argument, see Simion (2017). This section develops a rougher, shorter variety thereof, which will do for the purposes of this paper.

6 E.g. Frege $(1918,22)$.
} 
To check the plausibility of this claim, let us ask ourselves how one should read BAP in the first place. After all, the fact that some $\mathrm{x}$ stands to some $\mathrm{y}$ like inner to outer affords at least three possible readings: first, it could be that $\mathrm{x}$ and $\mathrm{y}$ are species of the same type, active in different environments. Alternatively, one might be a species of the other: $x$ but an inner manifestation of $y$, or the other way around. I will start with the most plausible reading, which also seems to be the one readily suggested by Williamson's formulation:

BAP1 Belief stands to assertion like inner phi-ing to outer phi-ing,

where phi is to be replaced by whatever it is that belief and assertion share, in spite of their differences in environment. Now, what phi stands for is of little importance for us here, but just for illustrative purposes, let us go along with Sosa (2010) and call it affirmation. As such, we get:

BAP1* Belief stands to assertion like inner affirmation to outer affirmation

Note that, at least at first glance, this formulation looks fairly plausible: intuitively, belief does seem to be, in some sense, the inner counterpart of assertion.

Note, however, that BAP1 fails to offer the desired kind of normative import, i.e., norm correspondence. That is, one cannot use BAP1 together with one's preferred account of the normativity of either belief or assertion in order to derive the relevant corresponding norm. After all, on this reading, belief and assertion are but species belonging to the same type. The fact that one is governed by a particular norm tells us precious little about what norm governs the other. To see this, consider waltzing and tango dancing; though they are both species of dancing, it does not follow that if $\mathrm{N}$ is a norm for waltzing, then $\mathrm{N}$ is also a norm for tango dancing. Similarly, on $\mathrm{BAP} 1$, one cannot argue from $\mathrm{N}$ being the norm for assertion to $\mathrm{N}$ being the norm of belief. On this reading, metaphysical parallelism does not warrant norm correspondence.

On a first approximation, what seems to be needed is that the genus is itself governed by the relevant norm; if $\mathrm{N}$ is a norm for dancing in general, it will be inherited by all of its species. If that is the case, what is needed here is that $\mathrm{N}$ is a norm governing the genus, i.e., in our example, affirmation, and thus gets inherited by both belief and assertion.

Crucially though, even so, the desired normative claim will still fail to come through. To see why, it will be useful to first turn to the alternative possible readings of the BAP and their purported normative import.

\subsection{Waltz shoes}

The obvious alternative reading is to take the claim to be that belief and assertion are such that one is a species of the other, which triggers norm transfer. Here is one such formulation, defended by people like Adler (2002) and Douven (2006):

BAP2 Belief is a species of assertion, to wit, subvocalized assertion or assertion to oneself (Douven 2006, 453) 
The thought would be, then, that norm correspondence drops out of this way to read BAP, since whatever the norm for assertion, it will govern all incarnations thereof, including subvocalized varieties, i.e. beliefs. Alternatively, of course, one might hold that, to the contrary, assertion is a species of belief (presumably vocalized belief), and the norm gets inherited in the other direction. Call this BAP3.

At first glance, both of these formulations seem to do the required normative trick. Think about dancing again: it looks as though, if there is a norm requiring one to wear light shoes for all dancing, one must, thereby, also wear light shoes for waltzing.

Alas, though, this normative import claim does not withstand closer valuetheoretic scrutiny either: norm transfer need not imply norm correspondence. To see why, note that the relevant norm for the type of shoes required for waltzing might be more demanding than the one governing dancing in general. This should be fairly easy to see: after all, what distinguishes waltzing from just any dancing is the fact that it is governed by some distinctive norms on top of the ones governing the genus it belongs to. In virtue of this, it can be that the relevant norm for waltzing is stronger than the one for mere dancing: and, as a matter of fact, waltz shoes are not just any light shoes, but medium heel, pointy, cross strapped light shoes.

If that is the case, though, again, correspondence need not follow from either BAP2 or BAP3. That is, just as in the case of waltz shoes, it can be that the epistemic requirement on the species is stronger than that on the genus. For instance, BAP2 does nothing to exclude the case of assertion being governed, say, by a justification norm, while belief is governed by a stronger, knowledge norm. In a parallel fashion, BAP3 is nicely compatible with a normative picture whereby assertion is only epistemically permissible if knowledgeable, while belief is governed by a less demanding norm. If that is the case, however, we will not be able to tell, just by looking at the norm governing, say, belief, what norm governs assertion, or the other way around. ${ }^{7}$

Of course, commonality may follow in the following trivial way: given that we are talking about a necessity claim, if, say, assertion will be governed by the stronger norm, the weaker condition governing belief will also be necessary for proper assertion. This result, however, is hardly interesting: surely, for instance, defenders of a knowledge norm of assertion would not want o say that they agree with defenders of a truth norm, just because the former entails the latter. What is at stake here-and what the literature is concerned with-is not merely identifying $a$ necessary condition, but identifying the strongest such necessary condition.

All in all, we don't seem to have much in the way of motivation to believe that normative correspondence is true. I say 'not much' rather than 'any' because, for all has been said here, there remains room for correspondence insofar as what is defended is a maximally strong norm for both assertion and belief. That is, BAP in all readings will do the intended work unaffected by the argument made by this paper if what is at stake is a certainty norm, for instance. It is easy to see, then, that

\footnotetext{
7 See Simion (2017) for how the argument can be easily reconstructed for the case of a constitutive norm.
} 
the normative requirement will merely be transferred from genus to species unaffected.

Note, though, a few things: first, again-depending, of course, on how the relevant notion of certainty is spelled out-many people will most likely fail to feel the attraction of defending such a demanding norm for either assertion or belief. ${ }^{8}$ Second, more importantly for present purposes, note that this still robs BAP of its advertised normative strength: after all, on this picture, BAP will only work in conjunction with a good defence of the relevant epistemic norm for whichever of the two - assertion or belief - is taken to be the type.

And third, even if we leave all this aside, on closer look, there is reason to doubt that even this pale claim to normative relevance stands. Here is why: recall that both BAP2 and BAP3, taken at face value, suffer from some degree of metaphysical awkwardness. It is, after all, a bit weird to claim that a mental state is a species of a speech act, or the other way around. What needs be the case, then, in order to avoid such aberration, is that we read both BAP2 and BAP3 non-literally, as making a restricted claim of the form:

BAP2* Belief is, in a relevant way, a species of assertion, to wit, subvocalized assertion

What BAP2* attempts to do is get rid of the metaphysical weirdness of the original formulation. The claim is that, for all we care, that is, in all respects that are relevant for the present discussion, belief is a species of assertion. Not in the sense that it is, itself, a speech act rather than a mental state, but in the sense that these considerations do not matter for present purposes.

Note, though, that this restriction robs BAP of even its last bit of normative flavour: after all, what this restriction amounts to is saying that that belief and assertion share some features, and others not. Again, however, just as in the case of them being species of the same type, the features they don't have in common can make all the normative difference.

One last thing still needs to be discussed: recall what was said at the end of section \#2.1 about affirmation: I was suggesting there that, even if we take assertion and belief to be species of the same genus, i.e. affirmation, and we find that a particular norm, call it $\mathrm{N}$, governs the genus, norm correspondence will still fail to follow. Now we are in a position to easily see why: first, it can still be the case that, although both assertion and belief inherit $\mathrm{N}$ from affirmation, one of them is governed by a stronger norm $\mathrm{N}+$. Second, even on the assumption that what is at stake is a maximally strong norm, the normative import we get is less than satisfactory; again, normative correspondence fails to obtain. Recall hat the thought was that what we wanted was to be able, in virtue of BAP, to come to deduce the norm of belief from knowing the norm of assertion or the other way around. On the picture we are left with, however, this will not work. After all, if we buy into BAP1, and come to discover that the norm of, say, assertion, is certainty, we will still not be able to ascertain whether that particular norm is inherited from the genus-

\footnotetext{
${ }_{8}^{8}$ Importantly, Williamson defends a knowledge norm where knowledge is understood to imply epistemic probability 1 .
} 
affirmation - as is, with the result that we may expect it to govern belief also, or whether affirmation is governed by a weaker normative requirement, in which case there is little we can ascertain about belief.

To sum up: we have looked at three possible readings of the belief-assertion parallel and argued that the BAP does not have the normative import it is often thought to have. On the one plausible, metaphysically unproblematic reading, on which belief and assertion are related to one another as inner to outer, nothing of normative interest follows from BAP. We then explored the thought that, in order to make sense of its employment in support of one normative account or another, BAP needs to be spelled out as making a (metaphysically weird) genus-species claim. However, it's not at all clear that the price is dialectically worth paying given that, as it turns out, even on this reading, BAP fails to deliver.

\section{Inheritance arguments}

If norm commonality does not follow from the belief-assertion parallel, that is, from metaphysical relations of sorts between the two, perhaps the target norm can be plausibly inherited through some variety of normative relations. One way this might be the case is through internal normative relations between belief and assertions themselves. Let us call this internal inheritance. Alternatively, inheritance can also come through some external route, from a third entity that bears some interesting normative relation with the two.

\subsection{Internal inheritance arguments}

Stipulating internal normative inheritance is the route pursued by Bach (2008) and Hindriks (2007). Roughly, the idea is that a knowledge norm for assertion (KNA) can be derived from the taking assertion to be the linguistic expression of belief, which gives rise to a belief rule ${ }^{9}$ on assertion, and a knowledge rule on belief. This idea has been developed in more detail by Hindriks. He starts from the following idea:

1. To assert that $p$ is to utter a sentence that means that $p$ and thereby expresses the belief that $p$.

Hindriks goes on to argue that, in situations of normal trust, which obtain unless it is permissible to lie, assertion is governed by a sincerity rule to the effect that one must express an attitude only if one has it. This gives us:

2. In situations of normal trust, one must: express the belief that $p$ only if one believes that $p$.

(1) and (2) imply

3. In situations of normal trust, one must: assert that $p$ only if one believes that $p$.

\footnotetext{
9 For the purposes of this paper, I use norm and rule interchangeably; nothing of essence hinges on this.
} 
Furthermore, Hindriks takes (3) to ground norm inheritance; that is, he takes it to be the case that, if (3) holds, and say:

4. One must only believe what one knows (the knowledge norm of belief, KNB), it follows that

5. In situations of normal trust, one must only assert what one knows (the knowledge norm of assertion, KNA).

In sum, the thought behind the Bach/Hindriks line is simple and elegant: since it is plausible that there is a belief norm on assertion, whatever the norm for belief is, it will get inherited by assertion.

Now, plausible as this might sound, there are, as a matter of fact, two important ways in which normative inheritance might fail to go through, in spite of normative dependence; first, there is a quantitative problem: transmission might fail. That is, it might be that, somewhere down the road, the norm in question gets affected-for instance, weakened or strengthened-by further normative requirements stepping in and, as a result, it fails to be inherited in its initial shape.

Second, there is a qualitative danger, pertaining to the type of norm we are talking about. That is, given that what we are after is an epistemic norm, we want to make sure the requirement that gets inherited strictly pertains to epistemic normativity.

Now, concerning the latter, doubts have been expressed in several places in the literature (e.g. Ball 2014; Simion and Kelp 2016) regarding the validity of the Bach/ Hindriks derivation, worrying that an equivocation on 'must' is at play in the argument. Roughly, the thought is that the Bach/Hindriks line attempts to derive an epistemic must - the epistemic norm of assertion in (5)_from a moral must governing 'normal trust' situations ((3)).

Even so, it may yet be possible to rescue Hindriks's argument. Why exactly should a moral sincerity rule be governing assertion in the first place? Why should we find it morally objectionable to make insincere assertions? One plausible answer is that insincere assertions are prone to induce false beliefs in others and that's something bad. But now notice that false beliefs are in the first instance an epistemic bad. One might think, then, that the moral sincerity rule is ultimately grounded in an epistemic sincerity rule, which, in turn, exists in order to minimize the epistemic bad of false belief.

What I will argue next, however, is that even if we charitably interpret the Bach/ Hindriks line to keep with sheer epistemic obligation from beginning till end, their conclusion still fails to follow.

Here is why: according to the Bach-Hindriks line,

(1) In normal trust situations, it is permissible to assert p only if you believe $\mathrm{p}$.

(2) It is permissible to believe p only if you know p,

(3) Therefore, in normal trust situations, it is permissible to assert p only if you know p. 
It is easy to see that, since the first premise features belief, while the second stipulates necessary conditions for permissible belief, and since belief does not imply permissible belief, the Bach-Hindriks line fails: deontic 'possible' does not work like this. ${ }^{10}$ There will be worlds where you believe impermissibly, but you still do, therefore you can permissibly assert. Obligation just does not transmit like the Bach/Hindriks line needs it to transmit. The lesson to take home, then, is the following: you might be criticisable for your beliefs, for breaking the norm of belief (say, for believing non-knowledgeably). However, insofar as you keep with the norm of assertion - in our case, the sincerity norm requiring you not to say things you don't believe yourself-your assertions will be criticism-proof.

One way to try and save the Bach/Hindriks argument, then, is to modify the second premise so as to feature permissible belief:

(1) In normal trust situations, it is permissible to assert p only if you permissibly believe $\mathrm{p}$.

(2) It is permissible to believe p only if you know p,

(3) Therefore, in normal trust situations, it is permissible to assert p only if you know p.

However, while this refurbished version of the Bach/Hindriks argument is, indeed, valid, it is not clear what in the Bach/Hindriks story can be taken to offer support to premise (1). It is plausible that normal trust situations are such that you should not assert things you don't believe yourself, i.e., as Bach and Hindriks would put it, you should not express a belief that you don't have. However, it is not clear why trust situations should also imply the stronger requirement of only expressing permissible beliefs. After all, plausibly, and according to the Bach/Hindriks line itself, assertion is a mere expression of belief, not of permissible belief.

\subsection{External inheritance arguments}

Here is one plausible claim: likely, our epistemic capacities are mainly meant to help us act well; as such, the kinds of things we believe and assert will, all things being equal, be the kinds of considerations we act upon. Here is, for instance, Robin McKenna on this issue: "[...] beliefs are the sorts of things that lead to actions and assertions. What each of us believes influences what we act on and assert, and in turn influences what those around us believe, act on, and assert (McKenna, Forthcoming).

In the light of this, another popular line of defence of CA in the literature takes commonality to follow from pragmatic considerations concerning what, at the end of the day, belief and assertion are, plausibly, for: storing/transmitting actionable

\footnotetext{
${ }^{10}$ I take the philosophical point to be enough here. Here is, though, the same point, but in more formal detail: on a narrow scope interpretation of the deontic claims in the argument, the conclusion fails to follow. On a wide scope interpretation, standard deontic logic vindicates the conclusion; however, this is widely taken to be a problem rather than a feature of standard deontic logic; very roughly, one core problem (but hardly the only one) for deontic inheritance is that 'ought' is context sensitive. For discussion, see, e.g. McNamara (2014).
} 
information. As such, it seems fairly plausible that, whatever the norm for action will turn out to be, belief and assertion alike will stand to inherit it.

Note, though, that this argument very closely resembles the Bach-Hindriks line, with the exception that the source of inheritance is taken to be an external one. That is, people defending this line want to get normative dependence between action on one hand, and belief and assertion on the other, to deliver normative inheritance. But, of course, one worry that readily arises is: if this line is but an external incarnation of the Bach-Hindriks argument, will it not suffer from the same transmission problems?

Fortunately, the answer is 'no'. And here is why. Recall that the Bach/Hindriks line turned out to be invalid. The problem was that, while the permissibility claim for assertion featured mere belief, knowledge was only necessary for permissible belief. Since the former does not imply the latter, the derivation failed. Now consider, in contrast:

(1) It is permissible to believe/assert $p$ only if it is permissible to act on $p$.

(2) It is permissible to act on p only if you know p.

(3) Therefore it is permissible to believe/assert p only if you know $\mathrm{p}$.

This derivation, of course, is fine, transmission-wise: the first premise stipulates necessary conditions for permissible assertion/belief that pertain to permissible action. Further on, the second premise also stipulates necessary conditions for permissible action. As such, in this case, normative transmission is successful. ${ }^{11}$

Here is this my worry concerning this line of argument, though; consider:

I. One must: dance only to songs one knows.

II. One must: jump in the lake only if one knows how to swim.

III. One must: only assert that $\mathrm{p}$ if one knows that $\mathrm{p}$.

It seems pretty obvious that III, in contrast to I and II, is a genuinely epistemic norm. What can we say about I and II? Well, for what is worth, they surely are norms guiding particular types of action; furthermore, they specify a particular amount of epistemic support needed for permissible action of these particular types. What type of permissibility are we talking about, however? Plausibly, aesthetic permissibility in the case of I (if there is such a norm as I to begin with, it is plausibly there to insure people don't fail really badly on the dance floor) and prudential in the case of II (after all, it is in view of the desirability of staying alive that the above norm holds). The upshot is that just because a norm regulating action features epistemic content - that is, just because it stipulates a particular amount of warrant needed for permissible phi-ing - it need not follow it is an epistemic norm. ${ }^{12}$

\footnotetext{
11 Also, the Deontic Transmission principle is, in this case, instantiated. Here is how the argument goes if we make DT explicit: (1) One ought to be in a position to permissibly act on p in order to permissibly believe/assert that p. (2) One ought to know in order to be in a position to permissibly act on p. (3) If one ought to $\mathrm{X}$ in order to $\mathrm{Y}$ and $\mathrm{Z}$ in order to $\mathrm{X}$, then one ought to $\mathrm{Z}$ in order to $\mathrm{Y}$ (DT). (4)Therefore, one ought to know in order to permissibly assert (from (1), (2) and (3)).

12 This should hardly be surprising: after all, the same is the case everywhere in the normative landscape: just because a norm regulates the appropriate speed, it need not follow it is a traffic norm, rather than, for
} 
If that is the case, though, that is, if the 'must' at stake in (2) need not be an epistemic must, the above derivation fails to go through. The defender of external inheritance needs to narrow down the permissibility at stake in her argument such that it is not at danger of equivocating on the relevant notion of 'must.'

Given that what we are interested in are epistemic norms governing assertion and belief - as opposed to, say, prudential, aesthetic or moral norms - we want to make sure that we are employing an epistemic must all through the argument. To this effect, what we need is a principled way to individuate epistemic norms for action from their prudential, aesthetic etc. counterparts, that does not merely rely on their featuring epistemic content. Absent such an account, the external inheritance derivation does not go through.

Now, given that her argument will only work in conjunction with an individuation proposal for epistemic norms for action, I take it that it is on the shoulders of the defender of external inheritance commonality to put forth such an account that does not assume individuation by content, but still serves her purposes well.

For now, let us take stock: we have seen that extant arguments, which aim to offer a rationale for the Commonality Assumption, fail. First, as it turns out, metaphysical parallelism (i.e., the belief-assertion parallel) does not support normative correspondence. Second, we have looked at people trying to derive normative inheritance from normative dependence. The internal variety thereof was shown to not go through due to transmission failure. The external incarnation, while successfully transmitting, was shown to be in danger of normative equivocation, absent a principled way to individuate epistemic norms.

In what follows, I look at one way to go about epistemic norm individuation that draws on epistemic functions; on this picture, belief and assertion are governed by epistemic norms in virtue of serving epistemic functions. I will show how the normative results that drop out of the functional analysis support non-commonality.

\section{Functionalism}

This final section indicates what one particular way to individuate epistemic norms would imply for the plausibility of the Commonality Assumption. I emphasize that this section is less ambitious than the rest of the paper, in that it only makes a conditional claim: if the functionalist proposal for epistemic norm individuation holds, the Commonality Assumptions runs into difficulties. Defending the functionalist proposal as such goes way beyond this essay's main goal, however.

According to proper functionalism about epistemic normativity, ${ }^{13}$ our epistemic traits and practices serve epistemic functions. Just like hearts were selected for their

\section{Footnote 12 continued}

instance, a moral norm. Several types of norms can regulate the degree of a gradable property needed for permissible action in a given context. But see (Simion 2018) for extensive discussion on how to (and how not to) individuate epistemic norms.

13 Defended in e.g. Graham (2012), Millikan (1984), Simion et al. (2016) and Simion and Kelp (2016). 
reliability in pumping blood and the corresponding biological benefit, epistemic traits and practices were plausibly selected for their reliability in generating epistemic benefit, which, in turn, helped us survive as a species. Because they generated epistemic goods-such as true beliefs, knowledge, understanding and so on-in our ancestors, they enabled them to survive-find out about the whereabouts of dangerous predators, find food-and reproduce, thereby replicating the same practice with the same function in their descendants. As such, our epistemic traits/ practices acquired the epistemic function ${ }^{14}$ of generating epistemic goods.

Now, in traits, artefacts and actions alike, functions generate norms (Millikan 1984; Graham 2012). There is such a thing as a properly functioning heart, a properly functioning can opener and a proper way to engage in sexual intercourse in order to serve the function of reproduction. Functions of a particular type come with associated norms of the corresponding type, which regulate the correct procedure to follow in order to reliably reach them.

Note, then, that there are two ways a functional device might go right, and two ways it may go wrong. The unhappy cases are: breach of the norm, i.e., malfunction (in the case of the heart, not beating) and failure to reach the corresponding purpose, i.e. failure to fulfill its function (not pumping blood) (Graham 2012, 449). The happy scenarios are, of course, proper functioning (beating) and function fulfillment (pumping blood).

Crucially, failure/success in one respect need not imply failure/success in the other. A trait can be malfunctioning - thus, in breach of the norm-and still fulfil its function (i.e., reach its aim), and the other way around: proper functioning need not imply function fulfilment. To see this, think of a situation where a surgeon takes the heart out of your chest, places it in a vat full of nutrients for a short while and plugs it to a pipe circuit filled with orange juice. Your heart, of course, will fail to fulfil its function of pumping blood under these circumstances; it will, as a matter of fact, be pumping orange juice. But this does not make it into a malfunctioning heart; to see this, compare it to a heart that has stopped pumping blood because it has been stabbed by a dagger. When functioning normally-whether in normal conditions or not-your heart will function properly, i.e. it will meet the norm constitutively associated with the purpose of pumping blood. It will work the way it is supposed to work, where the right way of working is partly constituted by fulfilling its function in normal conditions.

Also, not only need proper functioning not imply function fulfilment, but the other direction of the entailment need not hold either. After all, your dagger-stabbed heart can fulfil its function in spite of being malfunctioning, through some lucky circumstance, say, a blood circulation triggering magnetic field of sorts being in place.

Now, let us see how all this applies to epistemic normativity. One important and hard question for us here, and for epistemology at large, is what is the main function

\footnotetext{
${ }^{14}$ For this paper, I do not need to go more into technical detail regarding the precise account of functions I have in mind, since it would crowd up the paper unnecessarily: any account thereof will do for present purposes. However, the most widely employed account in recent literature (e.g. Graham 2012; Millikan 1984) is the etiological theory of functions.
} 
of our epistemic traits and activities; that is, what epistemic goods are they ultimately aimed at delivering. Among the main candidates in the literature, we can count truth (e.g. David 2005), knowledge (e.g. Williamson 2000) and understanding (e.g. Kvanvig 2003).

Fortunately, for the purposes of this paper, we do not need to settle this question. As it will turn out, no matter what the central function of our epistemic traits, we can plug it into the argument to follow and reconstruct it accordingly. Just for illustration, though, let us go along with Williamson and take the main telos ${ }^{15}$ of our epistemic traits and practices to be knowledge. The thought is to plug this assumption into the functional schema and see where it gets us when it comes to the corresponding norms for assertion and belief that drop out of this picture.

\subsection{Assertion}

Here's a plausible, broadly Grice (1989) thought: If there's such a thing as an epistemic norm for assertion out there in the first place, it is likely there to insure that assertion reliably delivers the epistemic goods ${ }^{16}$ we are using it for to the hearer. Now, what epistemic goods is assertion meant to deliver?

Although not essentially-I can, say, make assertions in a diary, which are usually not intended to affect any audience in any way-, characteristically, assertions will plausibly aim at generating testimonial knowledge in the audience. This seems like the main epistemic function of assertion (see, e.g., Kelp Forthcoming; Reynolds 2002; Goldberg 2015). Due to our physical and cognitive limitations, a lot of the knowledge we have is testimonial; thus, assertion is one of our main epistemic vehicles. ${ }^{17}$

But, if that is the case, it makes sense to regulate assertion with a knowledge norm: on most if not all accounts of testimony in the literature, ${ }^{18}$ in the vast majority of cases, the speaker needs to know in order to be able to generate knowledge in the

\footnotetext{
$\overline{15}$ Here and below I follow Graham (2012) and use 'function', 'telos', 'aim', purpose etc. talk interchangeably. Nothing here hinges on this.

${ }^{16}$ Does the functionalist picture eventually boil down to a variety of epistemic consequentialism? The answer is surely 'yes'. Will it then stand to suffer from the classical problems affecting this view? Fortunately, not. Here's the recipe for the classical anti-consequentialism line: you take an intuitively epistemic bad (say, a false, unjustified belief) and stipulate a great amount of epistemic goodness comes to attach to it, usually virtue of some otherworldly intervention-say, the Consequentialist Fairy offers you one million pieces of interesting knowledge for holding the respective unjustified false belief. Still, it does not look as though the false belief in question is epistemically permissible. Note, though, that 'fairy cases' are only a classical issue for act consequentialism, i.e. the view that, roughly, asks us to maximize goodness on all occasions. The functionalist picture, however, is a rule consequentialist picture: it asks us, roughly, to follow the rule that brings about the best highest amount of goodness, overall. In virtue of this, 'fairy cases' will not affect the functionalist story.

17 Is all knowledge on a par in this respect? Some items thereof seem entirely useless (e.g. about the number of blades of grass on my lawn). Perhaps it is more plausible to think that the epistemic function of assertion is generating interesting knowledge. For the purposes of this paper, I will take any such restriction on the relevant epistemic goal as read.
}

18 See Lackey (2008) for a nice overview. 
hearer. ${ }^{19}$ Given that, in the vast majority of cases, knowledge that $\mathrm{p}$ is on the speaker's side is necessary for generating testimonial knowledge that $\mathrm{p}$ on the hearer's side, the most reliable way for assertion to fulfil its function-i.e. to generate knowledge in hearers-is by being knowledgeable. As such, on a functionalist picture, an epistemically proper assertion will be a knowledgeable assertion.

\subsection{Belief}

In the previous section, we have seen that, if we take the main telos of our epistemic activities to be knowledge, what follows for assertion from a functionalist picture is a knowledge norm. Let us now look at what is the case with belief. On our knowledge-centric assumption, belief aims at being knowledgeable. Note, though, that if that is the case, that is, if knowledge is the relevant aim, there are good reasons to doubt that the corresponding norm will be a knowledge norm.

First, note that, when it comes to normativity at large, norms tend to not share content with the goal they observe. ${ }^{20}$ To see this, think of other norms we are familiar with. Take traffic norms: plausibly, they are meant to promote the aim of producing safe traffic. Now, note that norms meant to make it likely that the goal of safe traffic is reached have informative content, i.e. content that tells us how to go about reaching the goal in informative ways: 'Drive at most $50 \mathrm{~km} / \mathrm{h}$ within city bounds!', 'Stop at the red light!' etc. Similarly, take social norms; say you want to become a biologist; again, there are going to be norms that inform you how to go about it in order to make it very likely that you do become a biologist: 'Go to biology school!', 'Study hard!' Etc. Or take norms of chemistry: say you want to produce an antibiotic. The norms associated with this goal are going to tell you what ingredients to mix and under what conditions to mix them in order to produce an antibiotic. It would be less than informative if all these norms would share content with the goal; for instance, if the norm serving the goal of your becoming a biologist would merely say 'Become a biologist!', or the norms regulating antibiotics production would merely say 'Produce antibiotics!'. Similarly, it would be less than informative if the only driving norm we would have to guide us towards our goal of safe traffic would be 'Drive safely!'.

Now, crucially, the functionalist picture vindicates this thought. Recall that one central feature of the functionalist framework is that function fulfilment and proper functioning can come apart. My non-beating heart can pump blood via, say, some

\footnotetext{
19 Exceptions are few, and they roughly boil down to two types of cases: first, we have, again, 'selfless asserters', asserting on knowledge-level justification without belief (Lackey 2007) and 'compulsive liars' (Lackey 2008). Roughly, what happens in these cases is that, although the speaker intends to lie on a regular basis, some external intervention makes it so that she safely asserts the truth. Since both varieties of cases describe fairly unusual scenarios, they are unlikely to affect the argument made here; all I need is for it to be the case that knowledge is necessary and sufficient for generating testimonial knowledge in the vast majority of cases, and is therefore the most reliable route to function fulfillment.

20 Several people make essentially the same point, by use of very different terminology: McHugh (2012), for instance distinguishes between evaluative norms (ought-to-be's) and prescriptive norms (ought-todo's) and convincingly argues that a truth norm of belief is only plausible as an evaluative norm.
} 
weird magnetic field (function fulfilment), but it will not count as functioning properly. Also, my heart can be a perfectly properly functioning heart; if you take it out of my chest and place it in vat with nutrients, however, it will fail to fulfil its function of pumping blood. If knowledge is both the function and the norm of belief, however, properly functioning will entail function fulfilment, and vice versa; this, to say the least, paints a weird functionalist picture for belief.

If that is the case, however, it looks as though what we get on a functionalist picture is a milder norm for belief than for assertion. That is because, while in the case of assertion, the reliable way to fulfil its epistemic function is by being knowledgeable, in the case of belief the aim itself is knowledge. As such, plausibly, the norm for belief will just stipulate to follow the procedure that reliably gets beliefs to be knowledgeable beliefs.

If that is the case, on a functionalist framework, commonality is in trouble: belief and assertion are governed by distinct epistemic norms in virtue of serving different epistemic functions. Assertion aims to transmit knowledge, therefore it needs to be knowledgeable to begin with in order to achieve this. Belief aims to be knowledgeable; as such, the norm governing it is going to be milder; it is going to indicate the proper procedure to reach this aim reliably.

Recall, now, that I started this section by announcing that this paper will stay non-committal when it comes to the main epistemic telos debate. I have only picked knowledge for illustration purposes. Going back, it turns out that our results, as announced, generalize. And here is why: no matter what we take the main goal of our epistemic activities to be, the fact remains: the goal of assertion is to transmit it, while the goal of belief is to store it. If that is the case, on a functionalist picture, the norms for the two are likely to differ in content: no matter what the property at stake, assertion needs to have it (in order to reliably transmit it), while belief merely aims at acquiring it.

\section{Conclusion}

This paper has offered three reasons to distrust commonality, and one reason to believe non-commonality is true. I have looked at the extant arguments for the claim that assertion and belief are governed by one and the same epistemic norm, and concluded they fail. First, the belief-assertion parallel was shown to lack the advertised normative strength. Second, the claim that assertion inherits the norm of belief in virtue of being an expression thereof turned out to rest on a failed instance of deontic transmission. Third, the inheritance argument from the norm for action was proven suspicious of deontic equivocation.

In the end, I have argued that, on a functionalist normative picture, assertion and belief are not governed by the same epistemic norm, in virtue of their serving different epistemic functions.

Acknowledgements Many thanks to Jessica Brown, Sandy Goldberg, Patrick Greenough, Chris Kelp and Tim Williamson for all the help with this paper. 
Open Access This article is distributed under the terms of the Creative Commons Attribution 4.0 International License (http://creativecommons.org/licenses/by/4.0/), which permits unrestricted use, distribution, and reproduction in any medium, provided you give appropriate credit to the original author(s) and the source, provide a link to the Creative Commons license, and indicate if changes were made.

\section{References}

Adler, J. (2002). Belief's own ethics. Cambridge, MA: MIT Press.

Bach, K. (2008). Applying pragmatics to epistemology. Philosophical Issues, 18, 68-88.

Ball, B. (2014). Deriving the norm of assertion. Journal of Philosophical Research, 39, 75-85.

Brown, J. (2012). Assertion and practical reasoning: common or divergent epistemic standards? Philosophy and Phenomenological Research, 84(1), 123-157.

David, M. (2005). Truth as the primary epistemic goal: A working hypothesis. In M. Steup \& E. Sosa (Eds.), Contemporary debates in philosophy (pp. 296-312). Oxford: Blackwell.

Douven, I. (2006). Assertion, knowledge and rational credibility. Philosophical Review, 115, 449.

Frege, G. (1918). Der Gedanke. EIne Logische Untersuchung In Beiträge zur Philosophie des deutschen Idealismus, I, 58-77.

Goldberg, S. (2015). Assertion: the philosophical significance of a speech act. Oxford: Oxford University Press.

Graham, P. J. (2012). Epistemic entitlement. Nous, 46(3), 449-482.

Grice, P. (1989). Studies in the way of words. Cambridge, MA: Harvard University Press.

Hindriks, F. (2007). The status of the knowledge account of assertion. Linguistics and Philosophy, 30, 393-406.

Kelp, K. (Forthcoming). Assertion: A function-first account. Nous.

Kvanvig, J. (2003). The value of knowledge and the pursuit of understanding. Cambridge: Cambridge University Press.

Lackey, J. (2007). Norms of assertion. Noûs, 41, 594-626.

Lackey, J. (2008). Learning from words: Testimony as a source for knowledge. Oxford: Oxford University Press.

McHugh, Conor. (2012). The truth norm of belief. Pacific Philosophical Quarterly, 93(1), 8-30.

McKenna, R. (Forthcoming) Clifford and the Common Epistemic Norm. In American Philosophical Quarterly.

McNamara, P. (2014). Deontic logic. The Stanford Encyclopedia of Philosophy (Winter 2014 Edition), Edward N. Zalta (ed.). https://plato.stanford.edu/archives/win2014/entries/logic-deontic/.

Millikan, R. (1984). Language, thought, and other biological categories. Cambridge, MA: MIT Press.

Reynolds, S. (2002). Testimony, knowledge, and epistemic goals. Philosophical Studies, 110, 139-161. Simion (2017). Epistemic norm correspondence and the belief-assertion parallel. Manuscript.

Simion, M. (2018). No epistemic norm for action. American Philosophical Quarterly, 55(3), $231-238$.

Simion, M. and Kelp, C. (2016). Assertion: A function first account. Book Manuscript.

Simion, M., Kelp, C., \& Ghijsen, H. (2016). Norms of belief. Philosophical Issues, 26(1), 375-392.

Sosa, Ernest. (2010). Value matters in epistemology. Journal of Philosophy, 107, 167-190.

Williamson, T. (2000). Knowledge and its limits. Oxford: Oxford University Press. 